\title{
Critical Perspective: Named Reactions Discovered and Developed by Women
}

Julie A. Olsen

Smith College

Kevin M. Shea

Smith College, kshea@smith.edu

Follow this and additional works at: https://scholarworks.smith.edu/chm_facpubs

Part of the Chemistry Commons

\section{Recommended Citation}

Olsen, Julie A. and Shea, Kevin M., "Critical Perspective: Named Reactions Discovered and Developed by Women" (2011). Chemistry: Faculty Publications, Smith College, Northampton, MA.

https://scholarworks.smith.edu/chm_facpubs/11 


\title{
Critical Perspective: Named Reactions Discovered and Developed by Women
}

\author{
Julie A. Olson and Kevin M. Shea* \\ Smith College \\ Northampton, MA 01063 \\ kshea@smith.edu
}

\section{CONSPE C T US}

Named organic reactions. As chemists, we're all familiar with them-who can forget the Diels-Alder reaction? But how much do we know about the people behind the names? For example, can you identify a reaction named for a woman? How about a reaction discovered or developed by a woman but named for her male adviser? Our attempts to answer these simple questions started us on the journey that led to this Account.

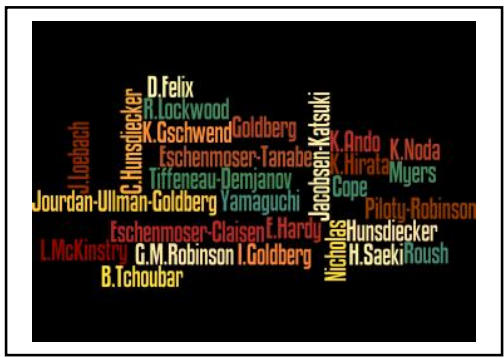

We introduce you to four reactions named for women and nine reactions discovered or developed by women. Using information obtained from the literature and, whenever possible, through interviews with the chemists themselves, their associates, and their advisers, we paint a more detailed picture of these remarkable women and their outstanding accomplishments.

Some of the women you meet in this Account include Irma Goldberg, the only woman unambiguously recognized with her own named reaction. Gertrude Maud Robinson, the wife of Robert Robinson, who collaborated with him on several projects including the Piloty-Robinson pyrrole synthesis. Elizabeth Hardy, the Bryn Mawr graduate student who discovered the Cope rearrangement. Dorothee Felix, a critical member of Albert Eschenmoser's research lab for over forty years who helped develop both the Eschenmoser-Claisen rearrangement and the Eschenmoser-Tanabe fragmentation. Jennifer Loebach, the University of Illinois undergraduate who was part of the team in Eric Jacobsen's lab that discovered the Jacobsen-Katsuki epoxidation. Keiko Noda, a graduate student in Tsutomu Katsuki's lab who also played a key role in the development of the Jacobsen-Katsuki epoxidation. Lydia McKinstry, a postdoc in Andrew Myers's lab who helped develop the Myers asymmetric alkylation. Rosa Lockwood, a graduate student at Boston College whose sole publication is the discovery of the Nicholas reaction. Kaori Ando, a successful professor in Japan who helped develop the Roush asymmetric alkylation as a postdoc at MIT. Bianka Tchoubar, a critically important member of the organic chemistry community in France who developed the Tiffeneau-Demjanov rearrangement.

The accomplishments of the women in this Account illustrate the key roles women have played in the discovery and development of reactions used daily by organic chemists around the world. These pioneering chemists represent the vanguard of women in the field, and we are confident that many more of the growing number of current and future female organic chemists will be recognized with their own named reactions.

\section{INTRODUCTION}

Named reactions have a critical place in the history and development of organic chemistry. They help chemists clearly and quickly communicate about complicated transformations, and they honor key contributors in the field for outstanding developments in synthetic and/or mechanistic knowledge. Beginning with our earliest 
undergraduate classes in organic chemistry through the most complex graduate courses in our research universities, named organic reactions are an organizing principle that have become part of the fabric of our beloved field. It is impossible to think about navigating the complex world of organic chemistry without the signposts of named reactions. ${ }^{1}$

However, how often do chemists wonder about the origins of these names? Why are some chemists immortalized and others forgotten? Why are some graduate students and postdocs included while other reactions bear only the name of the principle investigator? Unfortunately, discussions of these topics in print are rare. ${ }^{2}$ One exception is a fascinating 2010 article by Drahl in Chemical and Engineering News focused on the naming of the Heck (or Mizoroki-Heck) reaction that also addresses the broader question of how reactions are named. ${ }^{3}$ Reaction naming is far from straightforward, and no accepted rules exist for naming organic reactions. While most reactions are unnamed, the most practical and widely used transformations merit recognition with a name. Naming rights, however, do not belong to the person who discovered or developed the reaction. Instead, the broader organic chemistry community determines the worthy reactions through subsequent publications and citations.

So, how does a chemist's name end up attached to an organic reaction? Often, when a reaction is discovered and developed by a single lab, only the director receives credit since many coworkers contribute to the key body of work (e.g., Stille reaction). One exception to this rule is the Diels-Alder reaction in which Diels (the adviser) and Alder (the student) coauthored several papers on their "diene reaction", and Alder continued to publish on this transformation as an independent researcher. Coworkers are regularly named when their adviser is already recognized for other named reactions (e.g., CoreyFuchs reaction, Corey-Kim oxidation). Competing researchers who publish simultaneously often both receive recognition (e.g., Buchwald-Hartwig reaction), and reactions discovered by one lab and developed or modified by another often bear two names (e.g., Johnson-Claisen rearrangement). Also, as Drahl mentions in her article, ${ }^{3}$ reaction names do change over time.

Recently a question emerged in our lab focused on named organic reactions, "Are any named for women?" After talking to other organic chemists, this simple, yet intriguing question seemed to have appeal beyond the women studying organic chemistry at Smith College, so we decided to search for an answer to this query. We read the named reactions books in our library and even contacted several of the authors of these treatises. These efforts netted limited success; we identified only four reactions named for women: the Goldberg reaction, the Hunsdiecker reaction, the Jourdan-Ullman-Goldberg reaction, and the Piloty-Robinson pyrrole synthesis. ${ }^{4}$

This led us to wonder if the lack of reactions named for women related to the historical underrepresentation of women in chemistry or an effort to exclude women from this honor. As a historically male-dominated field, did societal norms of the past make it especially difficult or impossible for women to be recognized for their achievements? 
We then decided to modify our initial question in hopes of identifying more female organic chemists with pioneering roles in the discovery of named organic reactions. We hoped this would help us address the issue of women who may have been slighted in the past. Thus, our research question became, "Which named organic reactions were discovered or developed by women?" We were thrilled to discover eleven more women and nine additional reactions in answer to this question. These women played their key roles as undergraduates, graduate students, postdoctoral associates, or research associates on three continents and over the past 75 years.

In addition to simply identifying each woman as a name on a seminal publication, we have made every effort to contact these women and learn more about their lives in chemistry. We were greatly aided by peers, colleagues, and mentors who happily filled in biographical gaps for us. Where possible, we have included details from our correspondence in the descriptions to follow.

Based on our research, there is no evidence of gender discrimination in the naming of these reactions. The naming conventions we have outlined above are readily apparent in the names of the reactions that follow. We believe that only one woman in our study, Bianka Tchoubar (responsible for the development of the Tiffeneau-Demjanov rearrangement), was slighted by exclusion from the name of a reaction, and nothing indicates that this was related to her gender.

The accomplishments of the women in this study, described chronologically below, are impressive and worthy of celebration. They should justifiably serve as role models to the current generation of aspiring female organic chemists who will, hopefully, add to the length of this list in the future.

\title{
REACTIONS NAMED FOR WOMEN
}

\author{
Goldberg Reaction ${ }^{5}-1906$ \\ Jourdan-Ullman-Goldberg Reaction ${ }^{6}-1906$
}

\section{Irma Goldberg (1871- at least 1939) ${ }^{7}$}

Irma Goldberg was born in Moscow (1871) and moved to Geneva University in Switzerland to study chemistry in the 1890 s where she joined the research group of Fritz Ullmann. Goldberg published several articles and patents with Ullmann and independently between 1897-1912. Both of them moved from Geneva to the Technische Hochschule in Berlin in $1905 .{ }^{7}$

Ullman is well known for his pioneering work into the synthesis of functionalized aromatic compounds. In the early $20^{\text {th }}$ century, his lab reported key contributions on the production of substituted biphenyls from dimerization of aromatic iodides in the presence of copper (Ullmann coupling) and the synthesis of diaryl ethers upon combination of aryl halides with various phenol derivatives also in the presence of copper (Ullmann ether synthesis). One of Goldberg's research projects was to extend this strategy to the 
synthesis of aryl amine compounds. She conducted the critical research on the two reactions that bear her name between 1904-1908. ${ }^{7}$

The Goldberg reaction and Jourdan-Ullman-Goldberg reaction both involve formation of a nitrogen-carbon bond to an aromatic halide in the presence of copper. In the former case, the nitrogen-containing component is an amide; while in the latter, an amine is used as the partner for the aromatic halide. Goldberg and Ullman secured several patents for the use of potassium carbonate and copper catalysts in these processes. ${ }^{5,6}$

Following up on Jourdan's initial reaction with aniline and electron poor aryl halides to yield diarylamines, Goldberg and Ullman expanded the scope of the reaction to include a wider range of coupling partners by employing a copper catalyst and the mild base potassium carbonate. In Goldberg's single author 1906 paper, the reaction of aromatic amine 1 with bromobenzene (2) furnishes diarylamine 3 in $99 \%$ yield. ${ }^{8}$

\section{Scheme 1}<smiles>[R]OC(=O)c1ccccc1N</smiles>

1<smiles>[R]O[Na]</smiles>

2<smiles>O=C(OCc1ccccc1Nc1ccccc1)c1ccccc1</smiles>

3

In this same paper, she reported the reaction now known as the Goldberg reaction. The combination of benzamide (4) with bromobenzene (2) in the presence of potassium carbonate and catalytic copper provides the target amide $\mathbf{5}$ in $50 \%$ yield. ${ }^{8}$ Goldberg elaborated on these two methods in two more papers focused on the synthesis of triarylamines ${ }^{9}$ and the phenylation of primary aromatic amines. ${ }^{10}$

\section{Scheme 2}<smiles>NC(=O)c1ccccc1</smiles><smiles>Brc1ccccc1</smiles>

2<smiles>O=C(Nc1ccccc1)c1ccccc1</smiles>

5

Goldberg's other chemical interests included methods for the purification of acetylene and work in the industrially important field of organic dyes. Goldberg married Ullmann in 1910, and they eventually moved back to Geneva in 1923 when Ullmann returned to the faculty at Geneva University. ${ }^{7}$

Piloty-Robinson Pyrrole Synthesis ${ }^{11}-1918$

Gertrude Maud Robinson (1886-1954) 
Gertrude Maud Walsh was born in 1886 and entered the University of Manchester in 1904, where she obtained her undergraduate degree (1907) and master's degree in chemistry (1908). While working as a research assistant in Chaim Weizmann's lab at Manchester in 1909, Walsh met a graduate student in William Perkin's lab named Robert Robinson. They were married in 1912 and embarked on a voyage to Robert Robinson's first academic post at the University of Sydney, Australia. The Robinsons began their research partnership in Sydney which continued upon their return to Britain in $1915 .{ }^{12}$

Robert Robinson's interest in alkaloids is well known, ${ }^{13}$ and one of the Robinsons' early alkaloid investigations included development of a synthesis of tropine. They planned to synthesize this natural product starting from pyrrole. Their plan involved modification of the Fischer indole synthesis based on a detailed understanding of Fischer's transformation. Following up on Piloty's earlier studies, the Robinsons performed more detailed investigations including in depth studies of the reaction mechanism. ${ }^{14}$ In this paper, they demonstrated that ketazine 7 , derived from the combination of hydrazine and two equivalents of deoxybenzoin (6), can be efficiently converted into tetraphenylpyrrole (8) upon heating with hydrochloric acid. In their 1918 paper, the Robinsons beautifully outline the mechanism for the reaction which involves a variety of imine to enamine tautomerizations along with two key steps: a [3,3] sigmatropic rearrangement ${ }^{15}$ and elimination of ammonia. The Robinsons' structures are illustrated in Scheme 4, and, along with the text, do a remarkable job closely approximating the currently accepted mechanism.

\section{Scheme 3}

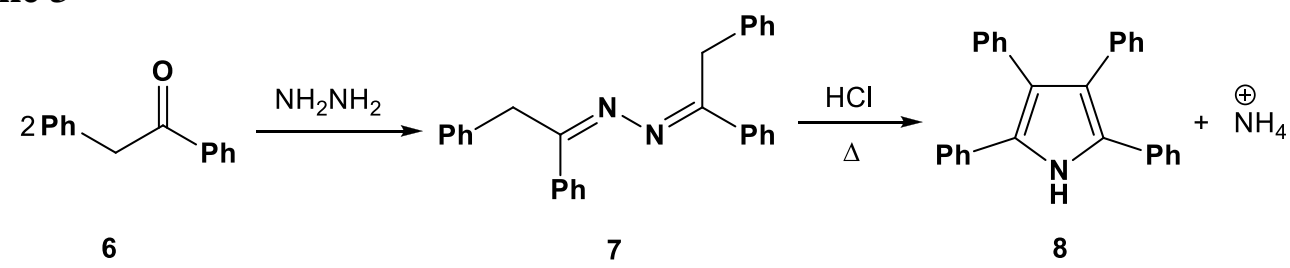

\section{Scheme 4}

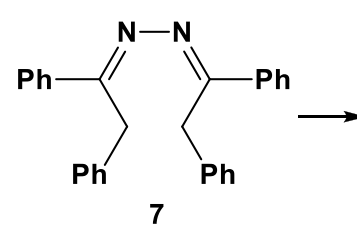

7

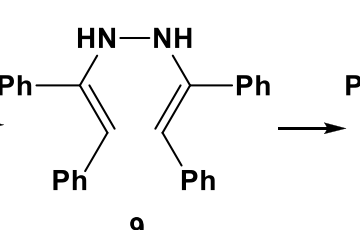

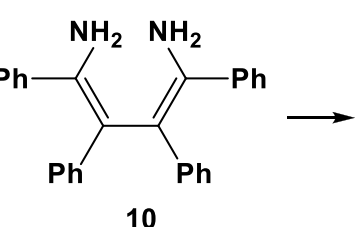

10

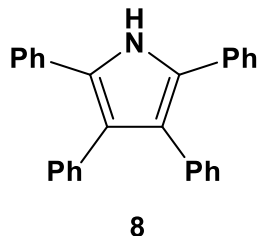

8

Throughout her life, Gertrude Robinson continued to pursue research in chemistry. She worked closely with Robert Robinson and also explored her own interests. Of her 38 papers from 1914 on, nine are single author publications and a further nineteen are only Gertrude and Robert Robinson. Their most fruitful collaborations focused on nitrogencontaining heterocycles and the chemistry of anthocyanins. Gertrude Robinson even encouraged Robert Robinson to join her in investigations into the chemical genetics of flower variations. For her numerous contributions to Oxford University, she was awarded an honorary MA degree in 1953. One year later, at the age of 68, Gertrude Robinson died from a sudden heart attack. ${ }^{12}$ 


\section{Hunsdiecker Reaction ${ }^{16}-1939$}

\section{Cläre Hunsdiecker (1903-1995)}

Cläre Dieckmann was born in Kiel, Germany (1903) and completed her PhD in chemistry in 1928 at the University of Cologne, Germany. She and her husband, Heinz Hunsdiecker, both conducted graduate research in Cologne in the research lab of Prof. R. Wintgen and were married in 1931. The Hunsdieckers were both hired by Egon Vogt of Chemische Fabrik Dr. Vogt \& Co. where they developed the reaction that came to bear their name. ${ }^{17}$

The Hunsdiecker reaction enables decarboxylation of silver carboxylates to yield alkyl halides. Heinz and Cläre Hunsdiecker described this method in several patents and one publication. ${ }^{18}$ They report the degradation of fatty acid salts into bromo-containing products in $65-80 \%$ yield. In one example, treatment of monomethyl adipate (11) with silver oxide furnishes silver carboxylate $\mathbf{1 2}$ which is decarboxylated upon addition of bromine to provide bromoester $\mathbf{1 3}$ in $\mathbf{7 5 \%}$ yield. Use of chlorine and iodine in place of bromine affords chloroesters and iodoesters, respectively. ${ }^{18}$ The mechanism for the Hunsdiecker reaction is a radical decarboxylation initiated by homolytic cleavage of the $\mathrm{O}-\mathrm{Br}$ bond formed upon addition of bromine in the second step. ${ }^{16}$

\section{Scheme 5}

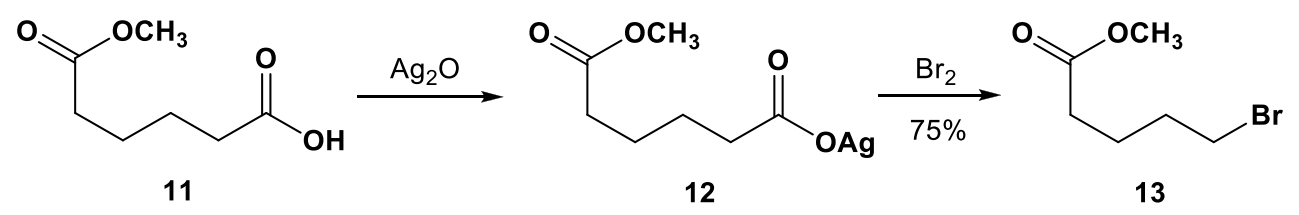

\section{REACTIONS DISCOVERED OR DEVELOPED BY WOMEN}

Tiffeneau-Demjanov Rearrangement ${ }^{19}-1937$

\section{Bianka Tchoubar (1910-1990)}

Bianka Tchoubar was born in Ukraine (1910) and immigrated with her family to France in 1924. She completed her undergraduate degree in chemistry at the Sorbonne in Paris in 1931. After obtaining a master's degree from the University of Paris in 1932, Tchoubar joined Marc Tiffeneau's research group at the Medical School in Paris. She quickly rose in stature in Tiffeneau's lab and soon directed her own research students, headed the Organic Chemistry Laboratory, and gained a research appointment at the newly created Centre National de la Recherche Scientifique (CNRS). ${ }^{20}$ Around this time Tchoubar and Tiffeneau published a series of papers on "molecular transposition" 
reactions, essentially pinacol and semi-pinacol rearrangements in cyclic 1,2-diols resulting in ring enlargements. In 1937, Tchoubar began her studies on a variation of the pinacol rearrangement resulting from the replacement of one alcohol in the diol with an amino group. These investigations would comprise her $\mathrm{PhD}$ dissertation and culminate in the development of the Tiffeneau-Demjanov rearrangement. Several unfortunate events including World War II and Tiffeneau's unexpected death in 1945, along with controversy related to her ideas on the mechanism of the reaction, delayed the acceptance of her thesis, entitled Contribution to the Study of the Ring Extensions: Nitrous Desamination of 1-Aminomethyl, 1-Cyclohexanols, until 1946. ${ }^{20}$ Tchoubar ultimately published her results highlighting the synthetic utility of the ring expansion process and her mechanistic explanation in a series of three consecutive articles in $1949 .{ }^{21}$ As is evident from these single-author papers, Tchoubar was the intellectual and experimental driving force behind the development of this reaction, and it is truly unfortunate that her exploits were not recognized as the Tchoubar rearrangement (or Tchoubar-Demjanov rearrangement).

The Tiffeneau-Demjanov reaction is at its most useful when employed to convert a cycloalkanone to its next larger cycloalkanone homologue (e.g., enlargement of cyclopentanone to cyclohexanone). This involves a three-step sequence with the actual named reaction coming in the final step. Treatment of cyclopentanone (14) with hydrogen cyanide yields cyanohydrin $\mathbf{1 5}$ which is hydrogenated to provide amino alcohol 16. The Tiffeneau-Demjanov reaction is initiated upon addition of nitrous acid causing the rearrangement to cyclohexanone (19). Tchoubar's mechanistic hypothesis for the rearrangement step involved generation of diazonium ion $\mathbf{1 7}$ from combination of the amine and nitrous acid. Loss of nitrogen yields carbocation 18 which quickly rearranges to the enlarged ketone followed by a proton transfer (PT) step. A contemporary analysis would likely avoid production of a primary carbocation and instead postulate an ion pair; however, Tchoubar's cationic intermediate is not far from the truth. Since its introduction by Tchoubar, this ring expansion strategy has seen widespread use in organic synthesis. ${ }^{19}$

\section{Scheme 6}

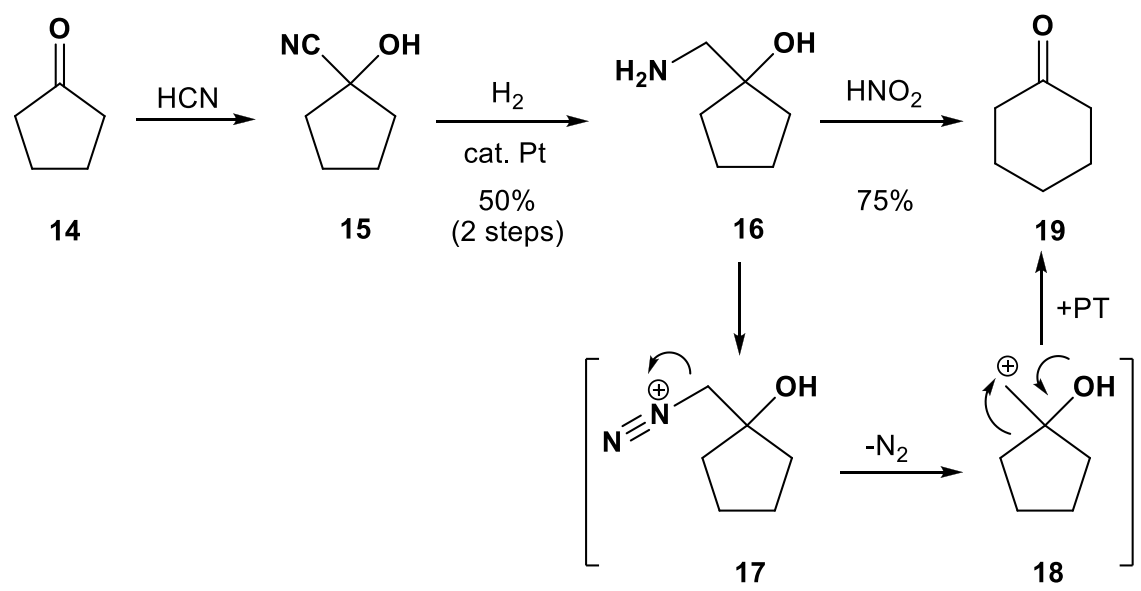


Tchoubar's research career at the CNRS flourished, including a prestigious appointment as Research Director from 1955-1978. In addition to her investigations into organic and organometallic reactions, her research team developed Spasmodex, a highly effective spasmolytic atropine medication. Tchoubar's interest in reaction mechanisms and talent in disseminating her deep knowledge on the subject are demonstrated by two popular books she authored, Reaction Mechanisms in Organic Chemistry (1960) and Salt Effects in Organic and Organometallic Chemistry coauthored with Andre Loupy (1988). The latter treatise was the final of Tchoubar's 140 publications spanning 56 years. ${ }^{20}$

\section{Cope Rearrangement ${ }^{22}-1940$}

\section{Elizabeth Hardy (1915-2008)}

In the 1930s, Arthur C. Cope's research group at Bryn Mawr College ${ }^{23}$ studied alkylation reactions of allylic enolates (e.g., 21). Elizabeth Hardy, a graduate student at Bryn Mawr, investigated one substrate in the series under examination and soon discovered what is now known as the Cope rearrangement. ${ }^{24}$ Hardy deprotonated enone $\mathbf{2 0}$ with sodium ethoxide in ethanol to yield delocalized enolate $\mathbf{2 1}$ and added allyl bromide to furnish $\alpha$ allylated product $\mathbf{2 2}$ in modest yield. Unlike the $\alpha$-alkylated products synthesized by a previous member of the lab (formed by reaction of the enolate with methyl iodide and ethyl iodide), Hardy's diene $\mathbf{2 2}$ transformed into a different material under the prolonged heating required for purification by simple distillation. Hardy undertook the arduous task of identifying the structure of this unknown compound and eventually proved that the thermal decomposition product was isomeric diene $\mathbf{2 3}$.

\section{Scheme 7}

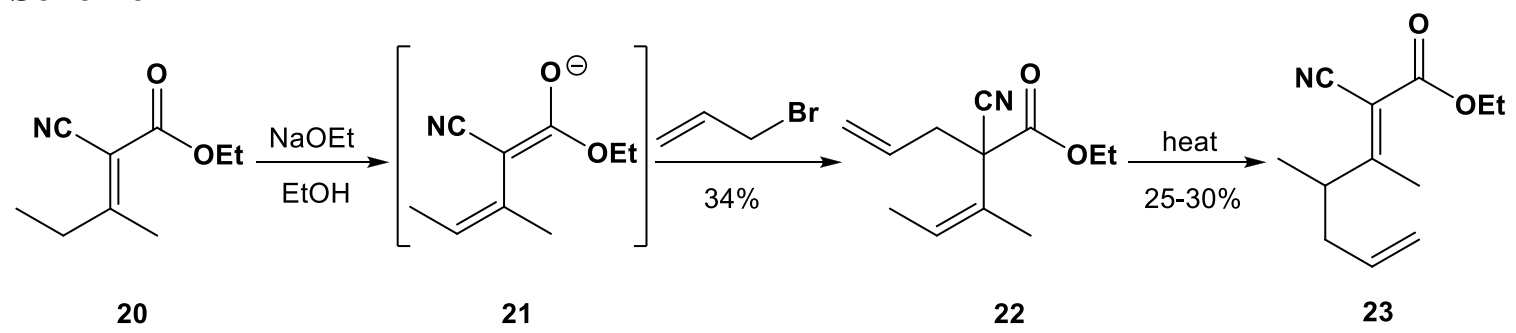

Cope and Hardy comment on this result in their seminal 1940 paper, "It appears probable that this rearrangement involving the migration of an allyl group in a three carbon system occurs for reasons similar to those responsible for the Claisen rearrangement of enol, phenol and vinyl ethers, and that the two types of rearrangement follow similar mechanisms." 24 Subsequent mechanistic investigations by Hardy proved that the rearrangement occurs over six atoms and is intramolecular (24 to $\mathbf{2 5}) .{ }^{25}$

\section{Scheme 8}




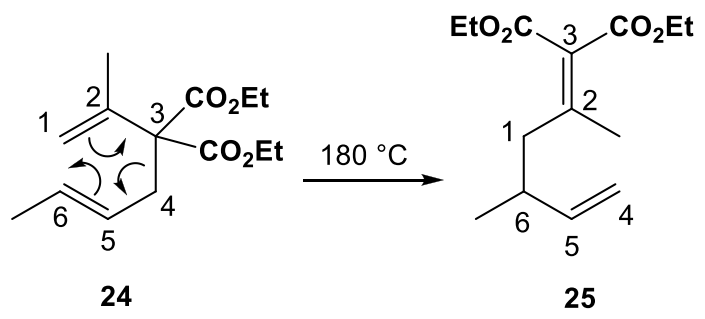

Thus, twenty-five years prior to Woodward and Hoffmann's theoretical explanation using molecular orbital theory, ${ }^{26}$ Hardy demonstrated the similarities between the Cope and Claisen rearrangements, which we now classify as $[3,3]$ sigmatropic rearrangements. The synthetic importance of the reaction discovered by Arthur Cope and Elizabeth Hardy cannot be overstated. ${ }^{22}$ Hardy's contributions were clearly significant, but Cope is immortalized singularly because of his continued development of the reaction with numerous other coworkers.

While in Cope's lab Hardy investigated several other projects and graduated from Bryn Mawr with her Ph.D. in chemistry in 1942. She continued her scientific career at the American Cyanamid Company where she worked on the research and development of organic dyes.

\section{Eschenmoser-Claisen Rearrangement ${ }^{27}-1964$}

\section{Dorothee Felix (1930- )}

Dorothee Felix earned her diploma in 1955 and $\mathrm{PhD}$ in 1959 at the Swiss Federal Institute of Technology (ETH). She conducted her graduate research in Albert Eschenmoser's lab and became a critical member of Eschenmoser's research team for the next four decades. Felix played key roles in the discovery and development of both the Eschenmoser-Claisen rearrangement and Eschenmoser-Tanabe fragmentation. Claude Wintner provided a vivid description of Felix's place in the Eschenmoser group in an account of his time in Eschenmoser's lab during three sabbatical stays between 1972 and $1990 .{ }^{28}$ Wintner described that two researchers, Jakob Schreiber and Felix, "oversaw essentially every practical aspect of [the lab's] experimental operation." He continued, "if I think of the most accomplished all-around experimentalists I have met in my life as a chemist, these two stand alone for me at the top."

\section{Katharina Gschwend (1939- )}

Katharina (Steen) Gschwend completed her undergraduate studies at the ETH in 1962 and then joined the research group of Albert Eschenmoser for her graduate work. Gschwend published three papers as a graduate student, two with Felix focused on Claisen rearrangements of allyl and benzyl alcohols. ${ }^{29}$

After graduating from Eschenmoser's lab with her $\mathrm{PhD}$ in 1965, Gschwend joined Conrad Bloch's group at Harvard for postdoctoral research focused on vitamin K. 
Subsequent to Harvard, Gschwend left chemical research and pursued careers in pharmacy, financial planning, and small business ownership.

In 1964, Felix and Gschwend reported a modification of the Claisen rearrangement that furnished unsaturated amides in high yields and stereoselectivities. ${ }^{29}$ Felix and Gschwend combined cyclic allylic alcohol $\mathbf{2 6}$ with the dimethyl acetal of dimethylacetamide in refluxing xylenes to yield $\gamma, \delta$-unsaturated amide $\mathbf{2 8}$ in $70 \%$ yield. As explained by Woodward and Hoffman in 1965, the mechanism of a Claisen rearrangement is a [3,3]-sigmatropic rearrangement of an allyl vinyl ether (e.g., 27). ${ }^{26}$ The reaction proceeds via chair-like transition state 29 and affords excellent stereocontrol for the formation of a new stereocenter at one terminus of the newly formed carboncarbon bond (C6 in 28). Felix and Gschwend provided experimental details for various Eschenmoser-Claisen rearrangement reactions of allylic and benzylic alcohols in a subsequent paper. $^{29 \mathrm{~b}}$ This useful transformation has seen extensive use in organic synthesis. ${ }^{27}$ As a modification of a known organic reaction, Eschenmoser's name alone appears alongside Claisen's in the title of this reaction.

\section{Scheme 9}

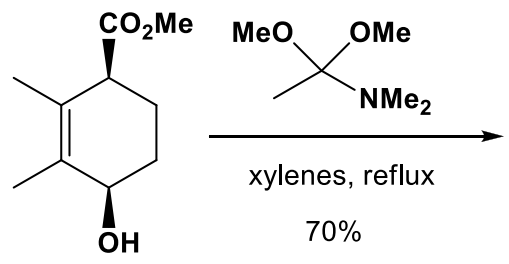

26

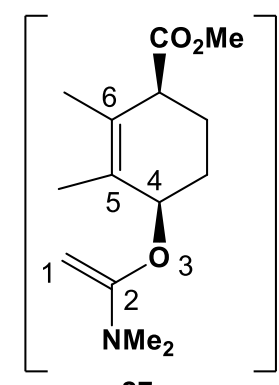

27

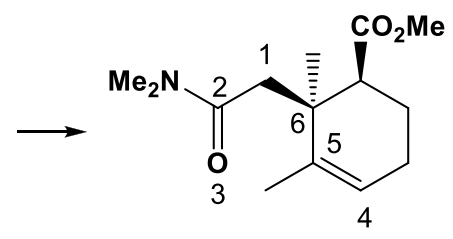

28

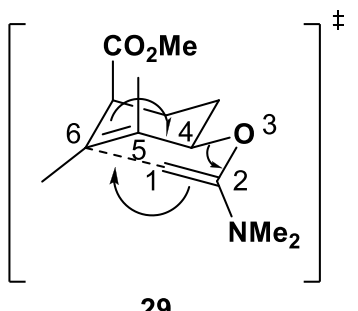

Eschenmoser-Tanabe Fragmentation ${ }^{30}-1967$

\section{Dorothee Felix (1930- )}

In 1967, Eschenmoser and Felix, ${ }^{31}$ and separately Tanabe, ${ }^{32}$ described this fragmentation reaction; thus, this useful transformation recognizes both Eschenmoser and Tanabe. Felix demonstrated the power of this method for the production of macrocyclic alkynes in her first publication. As with all Eschenmoser-Tanabe fragmentations, an enone is converted to an epoxyketone, then an epoxyhydrazone before cleavage to furnish an alkynone. In their initial example, Felix and Eschenmoser began with bicyclic enone 30 
which was converted to epoxide 31 and then epoxyhydrazone 32. Treatment of this compound with sodium methoxide yielded anion 33 which promoted epoxide opening and the formation of alkoxide 34. Fragmentation of $\mathbf{3 4}$ yielded the 15-membered ring product alkynone 35. ${ }^{31}$ Felix's subsequent publication demonstrated the broad scope of this reaction. Mono- and polycyclic epoxyketones were successfully transformed into the corresponding epoxyhydrazones and fragmented in good yields to provide a variety of alkynone products. $^{33}$

It is unfortunate for Dorothee Felix that Tanabe published a similar reaction simultaneously with the paper from her lab. If Tanabe were not also working on this transformation, Felix's sustained contributions to the development of this reaction, along with Eschenmoser's recognition for other accomplishments, might have led this reaction to become known as the Eschenmoser-Felix fragmentation.

\section{Scheme 10}

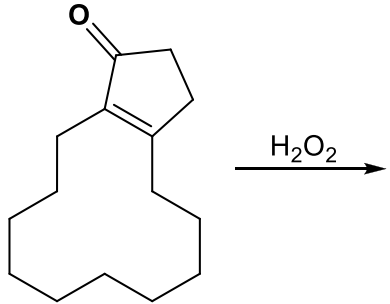

30 $\mathbf{N} \equiv \mathbf{N}+\Theta_{\mathbf{T}} \mathbf{s}$

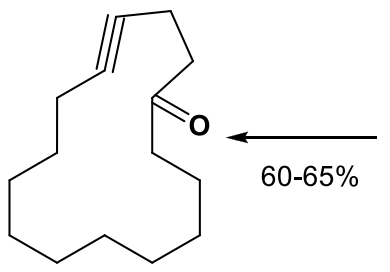

35

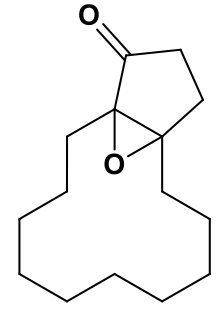

31

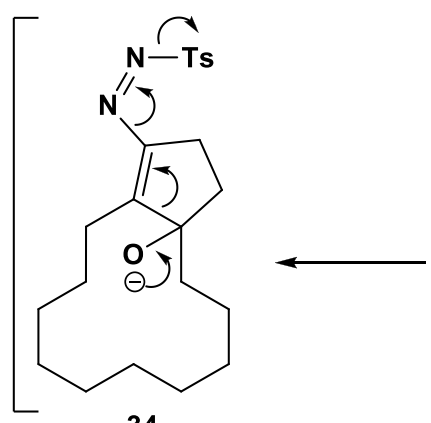

34

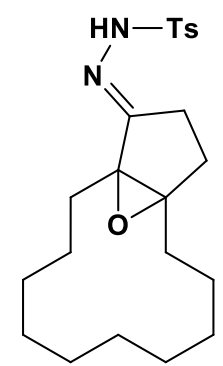

32<smiles>COc1ccccc1</smiles><smiles>[3H]N([3H])/N=C1\CCC2(CCCCCCCCCC2)O1</smiles>

33

Nicholas Reaction ${ }^{34}-1977$

\section{Rosa Lockwood (1943- )}

Kenneth Nicholas began studying the chemistry of dicobalt hexacarbonyl-alkyne complexes as a graduate student at the University of Texas around 1970. As an assistant professor at Boston College in the late 1970s, Nicholas ${ }^{35}$ investigated the use of these cobalt-complexed alkynes in carbon-carbon bond-forming reactions. His graduate student who pursued these investigations was Rosa Lockwood, a native of Brazil, who came to the United States with a graduate scholarship from the Brazilian government. 
It was known that cobalt-alkyne complexes stabilized adjacent carbocations (e.g., 38), but the reactivity of these intermediates was virtually unexplored when Lockwood began her experimental work. She demonstrated the utility of these carbocations as propargylating agents for several electron-rich aromatic nucleophiles. ${ }^{36}$ These Friedel-Crafts reactions proceeded in high yield and could be run stepwise or in a one-pot procedure. For example, propargyl alcohol 36 can be cobalt complexed to yield cobalt-alkyne complex 37. Addition of tetrafluoroboric acid yields stabilized carbocation $\mathbf{3 8}$ that reacts with anisole to furnish para disubstituted benzene 39. Oxidative decomplexation with iron(III) provides target alkyne $\mathbf{4 0}$ in $\mathbf{4 3 \%}$ overall yield.

\section{Scheme 11}

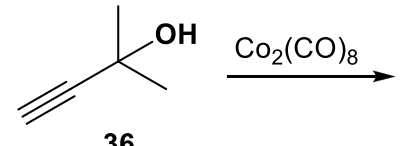

36

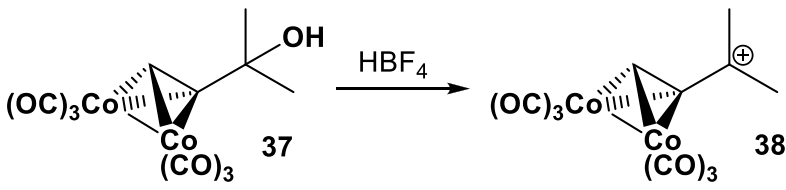<smiles>COc1ccccc1</smiles><smiles>C#CC(C)(C)c1ccc(OC)cc1</smiles>

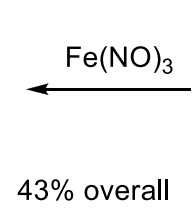

The synthetic power of this new method was clearly stated by Nicholas and Lockwood, "1) acid-catalyzed rearrangements, which plague uncomplexed terminal propargylic alcohols, are avoided; 2) quaternary centers may be generated $\alpha$-to the synthetically versatile acetylene function and 3) since propargyl alcohols are derived from acetylide additions to carbonyl compounds, in effect, this method constitutes a flexible carbonyl geminal dialkylation." 36 Since Lockwood's discovery of this reaction, the scope has expanded to include reactions with other carbon and heteroatom nucleophiles. ${ }^{34}$

This seminal paper on reactions involving cobalt-complexed alkynes was the only publication of Rosa Lockwood's career. Nicholas continued to explore this transformation with other coworkers, and the reaction bears his name alone.

After completing her Master's degree at Boston College, she briefly returned to her native Brazil before coming back to the Boston area. Lockwood worked in the Newton public schools as a teachers' assistant for math and science for many years until her retirement in 2001. She now continues her work with students on a part-time basis. 


\section{Kuniko Hirata (1953- ) Hiroko Saeki}

In the late 1970s, Masaru Yamaguchi's research group at Kyushu University in Fukuoka, Japan became interested in developing reagents to promote esterification for the synthesis of macrocyclic lactones. Kuniko Hirata and Hiroko Saeki joined a team of chemists under the direction of Yamaguchi who focused on generating mixed anhydrides (like 42) in the presence of 4-dimethylaminopyridine (DMAP) to promote lactonization. Hirata, Saeki, and coworkers synthesized a variety (more than 15) of mixed anhydrides bearing substituted benzene rings and determined that both anhydride formation and lactonization were favored when starting with 2,4,6-trichlorobenzoyl chloride. They demonstrated the utility of this strategy starting with several unfunctionalized hydroxy acids like $\mathbf{4 1}$ which yield the desired lactone $\mathbf{4 3}$ in $67 \%$ yield. ${ }^{38}$

\section{Scheme 12}<smiles>CCCCCCCCCCCCCC(=O)O</smiles>

41
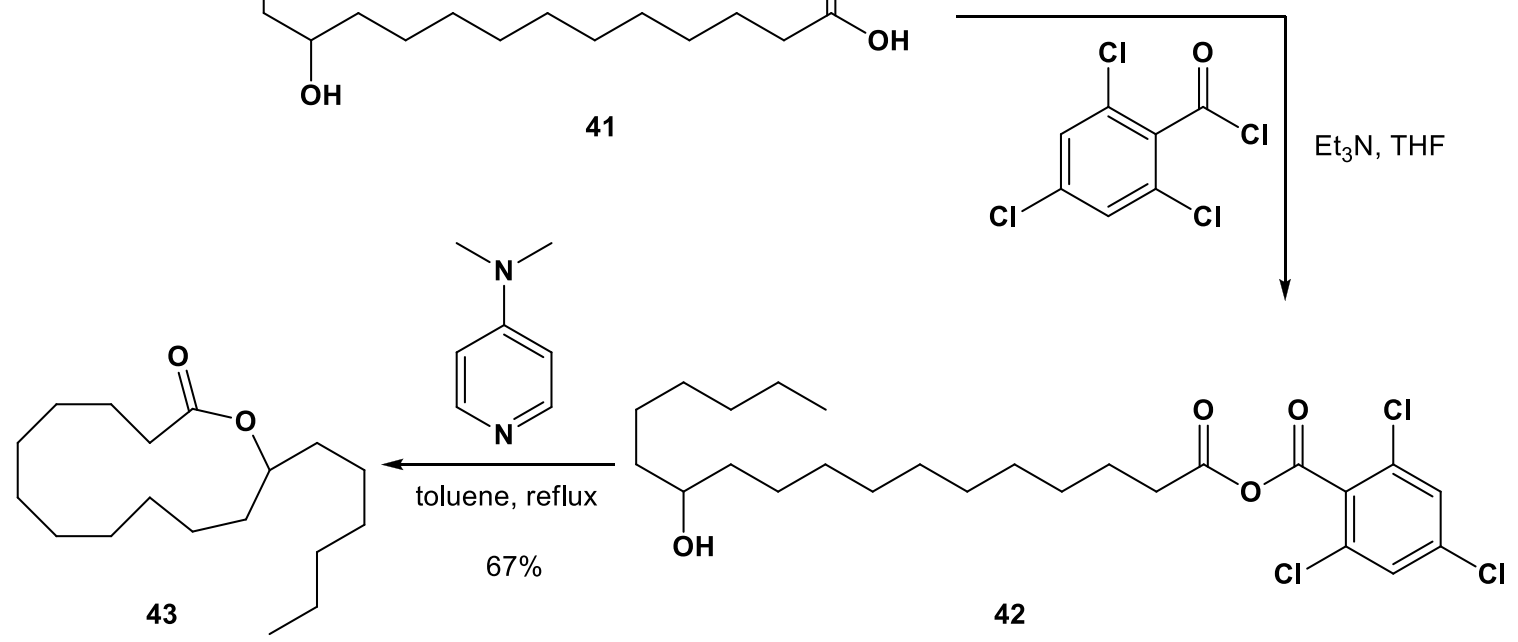

Hirata, Saeki, and coworkers then demonstrated that this protocol can successfully transform more highly functionalized, acid sensitive hydroxy acids into macrocyclic lactones. Their example involved conversion of hydroxy acid $\mathbf{4 4}$ into 12-membered lactone 45 in $46 \%$ yield. The reaction developed by Hirata and Saeki has become an important method for the synthesis of naturally occurring macrocyclic lactones. ${ }^{37}$ Yamaguchi, as the head of the lab, is given sole recognition in the name of this reaction.

\section{Scheme 13}



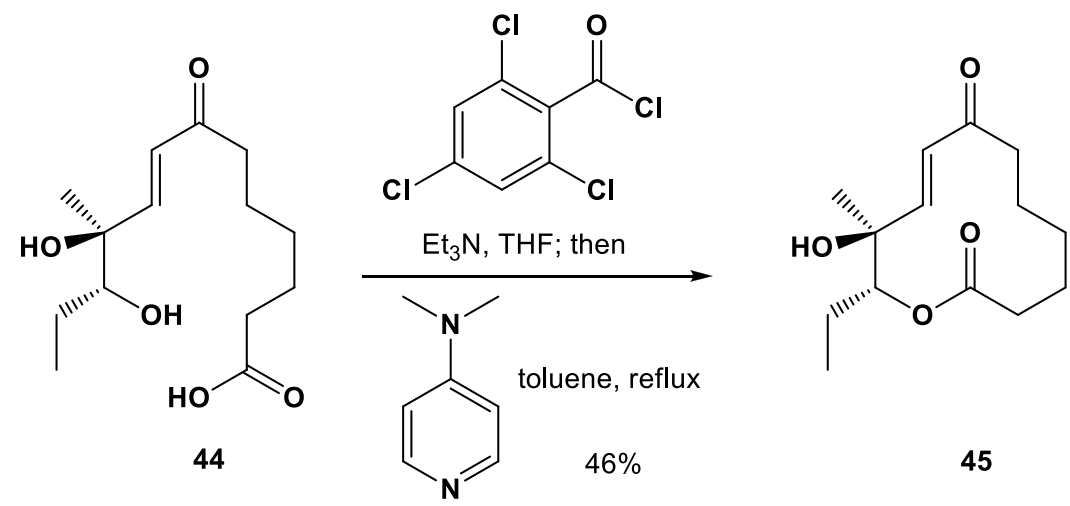

45

Hirata obtained her bachelor's and master's degrees from Kyushu University in 1976 and 1978, respectively. Hirata then joined the Department of Physics at Osaka University as a technical staff member. In 2005, she moved to her present position as a laboratory instructor in the Department of Chemistry at Osaka. Our efforts to find more information about Hiroko Saeki proved fruitless.

\section{Roush Asymmetric Alkylation ${ }^{39}-1988$}

\section{Kaori Ando (1956- )}

In the early 1980s, many research groups around the world focused on the development of nucleophilic reagents capable of adding in an asymmetric fashion to aldehydes. Both asymmetric aldol reactions (enolate nucleophiles) and alkylation reactions (alkyl nucleophiles) were studied intensely during this period. As an assistant professor at the Massachusetts Institute of Technology (MIT) ${ }^{40}$ William Roush focused his efforts on asymmetric addition reactions of allyl and crotyl nucleophiles. His lab demonstrated the efficacy of diisopropyl tartrate-containing allylboronate 47 in reactions with aldehydes like 46 to yield nearly enantiopure alcohol products like $48 .{ }^{39}$ On the heels of this success, Roush's research focus turned to crotyl nucleophiles capable of forming two stereocenters in the carbon-carbon bond-forming step. This is the project that Kaori Ando joined upon her arrival at MIT as a postdoctoral researcher in 1986.

\section{Scheme 14}

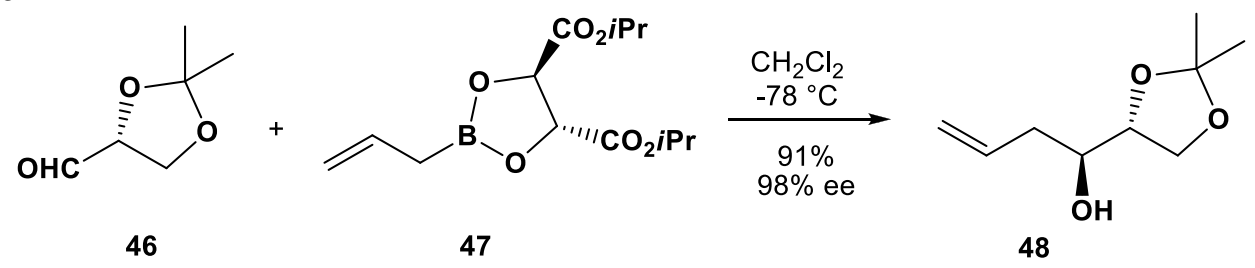

Ando was born in Okayama, Japan in 1956 and earned her bachelor's degree in chemistry from the University of Tokyo in 1981. Continuing on at Tokyo, Ando performed her graduate research in Kenji Koga's lab focusing on asymmetric alkylation and asymmetric Michael reactions. Ando graduated with her PhD in 1986 and then began her postdoc at MIT with Roush. 
Ando's research in Roush's lab culminated in three papers highlighting what ultimately became known as the Roush asymmetric alkylation reaction. ${ }^{41}$ She first described the straightforward preparation of (E)- and (Z)-crotylboronates followed by their reaction with achiral aldehydes. Ando developed highly efficient and reproducible methods for the production of both crotylboronate alkene isomers. Thus, trans 2-butene (49) and cis 2-butene (51) can each separately be transformed into the corresponding trans and cis crotylbotonates, $\mathbf{5 0}$ and $\mathbf{5 2}$, respectively, in greater than $70 \%$ yield and $98 \%$ geometric purity. 


\section{Scheme 15}
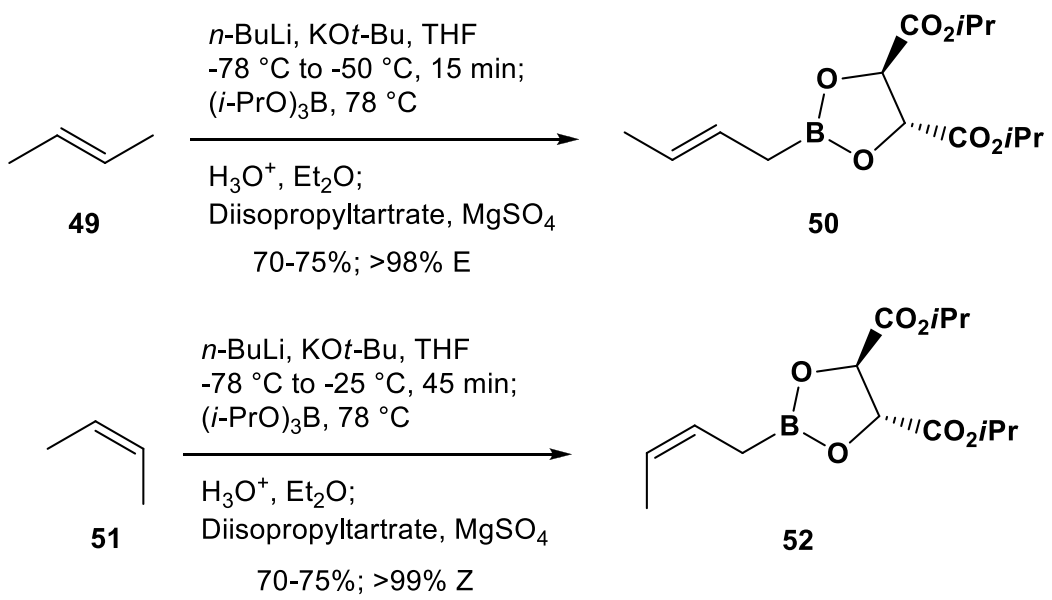

Ando then described highly selective reactions of these two reagents with a variety of simple aldehydes to furnish secondary alcohol products. The reactions proceeded in high yield with excellent anti:syn ratios (trans boronate $\mathbf{5 0}$ favors anti products, while cis boronate 52 favors syn products) and high enantiomeric excess. For example, combination of aldehyde $\mathbf{5 3}$ with crotylboronate $\mathbf{5 0}$ furnishes homoallylic alcohol $\mathbf{5 5}$ in $86 \%$ yield and $84 \%$ ee with a greater than $99: 1$ antisyn ratio. Ando explained the outstanding selectivity of this transformation by invoking the well-known chair-like transition state 54. Finally, Ando described applications of the asymmetric alkylation reactions to the synthesis of a portion of the natural product rifamycin S. ${ }^{41}$ Along with many other coworkers in the Roush lab, Ando contributed significant results to the development of this reaction. Consequently, Roush is highlighted singly in the name of this transformation.

\section{Scheme 16}

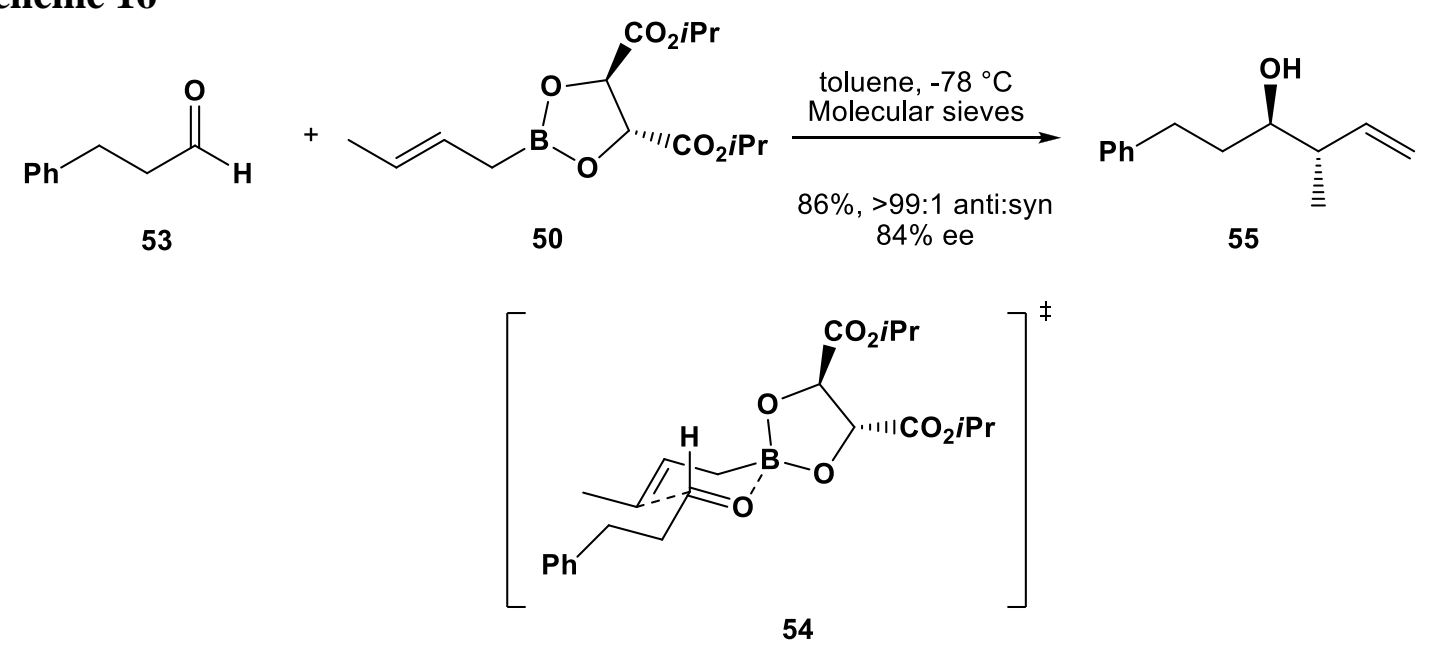

After leaving MIT, Ando returned to Japan as an associate professor at Teikyo University in 1988. She moved to the University of Ryukyus as an associate professor in 1993 and was promoted to full professor in 2004. Ando is presently a full professor at Gifu University, having moved there in 2007 . Her research interests as an independent 
investigator have focused on both experimental and theoretical topics in organic chemistry.

\section{Jacobsen-Katsuki Epoxidation ${ }^{42}-1991$}

\section{Jennifer Loebach (1968- )}

Jennifer Loebach joined Prof. Eric Jacobsen's ${ }^{43}$ research group at the University of Illinois in 1988. Loebach, an Eli Lilly Undergraduate Summer Scholar, was Jacobsen's first undergraduate research student and joined a team of two other students investigating epoxidation catalysts. Their research into the enantioselective epoxidation of unfunctionalized alkenes catalyzed by manganese(salen) complexes resulted in Jacobsen's first independent publication and Loebach's sole paper with the Jacobsen lab. ${ }^{44}$

At the outset of their investigation, asymmetric epoxidations were only possible for alkenes with directing functional groups, like alcohols. ${ }^{42}$ The research of Loebach and coworkers demonstrated that alkenes lacking heteroatom substituents could also be catalytically epoxidized in high yield with high enantioselectivities. The group began their experiments by synthesizing the key chiral catalyst. The requisite manganese(salen) complex 60 can be easily prepared in three steps from 56 and 57 . Epoxidation of a variety of mono-, di-, and trisubstituted olefins demonstrated the utility of this manganese catalyst. For example, alkene $\mathbf{6 1}$ reacts with catalyst $\mathbf{6 0}$ to yield epoxide $\mathbf{6 2}$ in $73 \%$ yield and $84 \%$ enantiomeric excess. The Jacobsen lab and others have continued the development of this valuable method for the asymmetric epoxidation of alkenes, and its use has become widespread in academic and industrial labs. ${ }^{42}$ 


\section{Scheme 17}
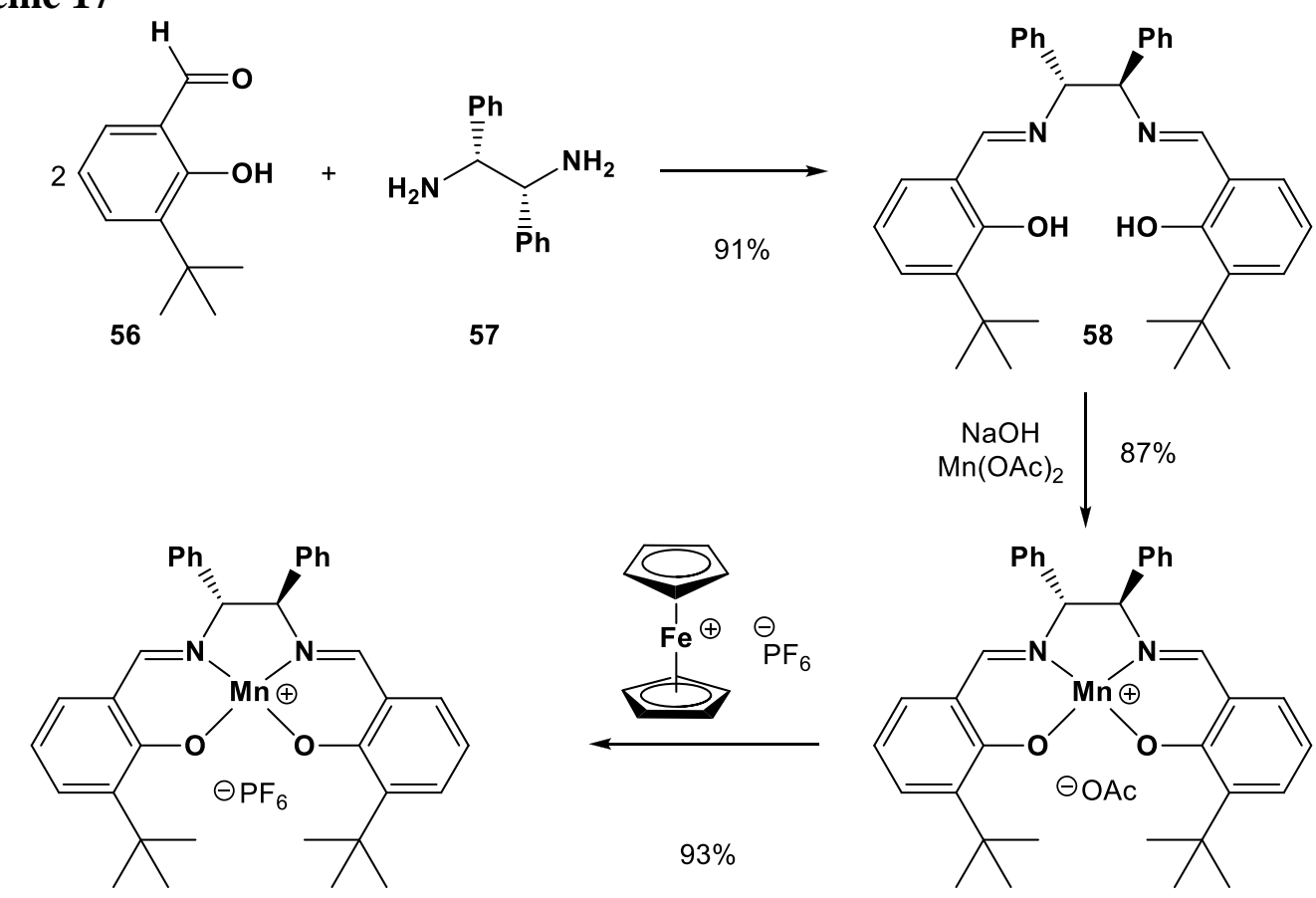

60

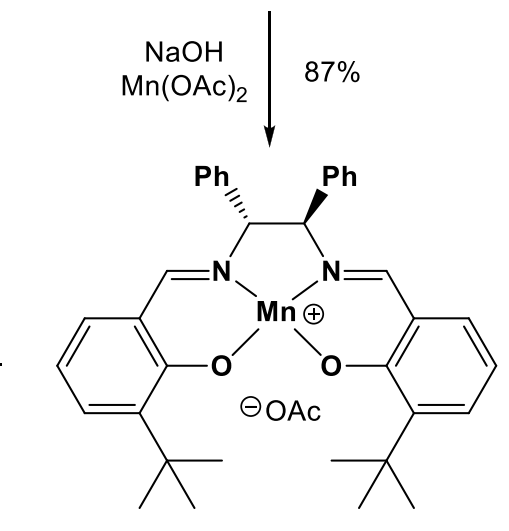

59

\section{Scheme 18}

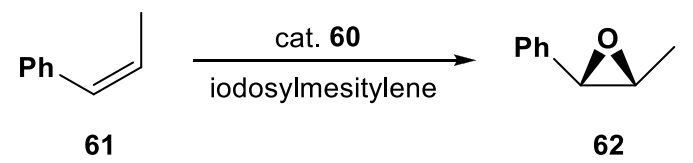

Loebach graduated from Illinois in 1990 and began her graduate research as an NSF Fellow at MIT in Rick Danheiser's lab. Loebach graduated from MIT with her PhD in 1995 then completed a postdoc at Princeton before moving to the department of medicinal chemistry at Merck. She is now pursuing a career as a patent lawyer at a law firm in Boston.

\section{Keiko Noda}

Keiko Noda joined Tsutomu Katsuki's research group at Kyushu University in Fukuoka, Japan in 1988 as a fourth-year graduate student. She began the lab's investigations into asymmetric epoxidations using manganese(salen) catalysts. Several other researchers joined her, and the project yielded three publications between 1990-1991, resulting in Katsuki sharing recognition with Jacobsen for the manganese(salen) catalyzed epoxidation of alkenes. ${ }^{45}$

Noda's investigations focused on manganese(salen) complexes with structures very similar to molecules Loebach researched. While Loebach's catalysts contained ortho tbutyl groups, Noda's compounds incorporated a bulky chiral center at both ortho positions. She also studied catalysts with and without methyl groups in the meta 
positions and determined that this catalyst was superior in some reactions. For example, catalyst 64 promotes oxidation of stilbene (63) with iodosylbenzene to furnish chiral epoxide 65 in $95 \%$ yield and $48 \%$ ee. Noda's catalysts are more complicated to synthesize than those prepared by Loebach. While the final three steps are nearly identical (see Scheme 17), Noda's salicylaldehyde substrates are prepared in eight steps while Loebach's are commercially available. ${ }^{45}$

\section{Scheme 19}

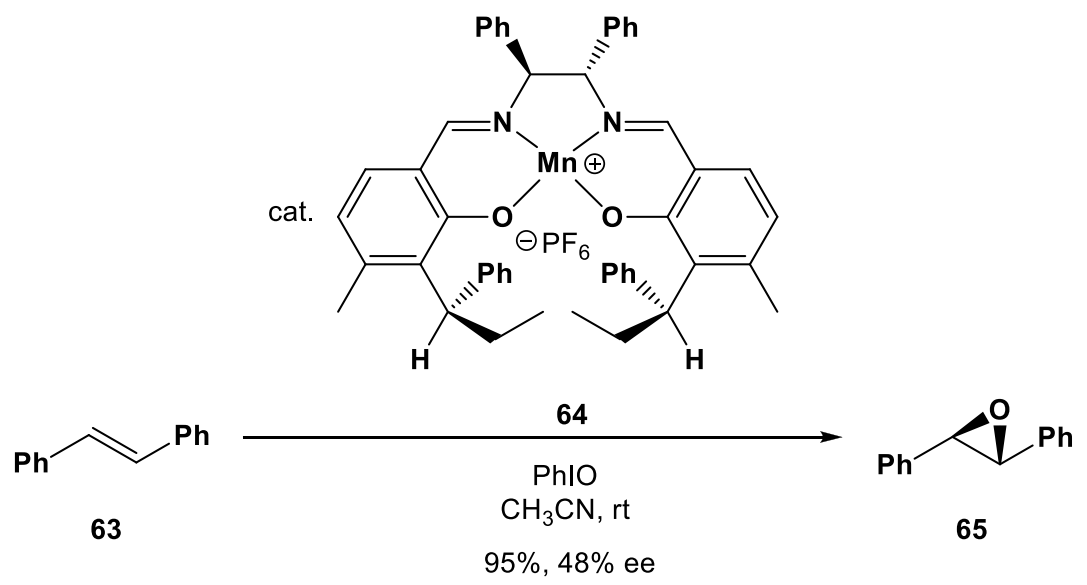

Due to the ease of synthesis and superior results in reactions with Z-alkenes, Jacobsen's catalyst has seen much more widespread use. In general, trans-1,2-disubstituted olefins like stilbene react with greater asymmetric induction in the presence of Katsuki's catalyst.

Noda completed her $\mathrm{PhD}$ in 1989 and became a high school teacher in Japan.

Both Loebach and Noda were single members of larger research programs that coalesced into independent publications of similar reactions. Had Jacobsen or Katsuki not worked on this transformation, it would either be known as the Jacobsen epoxidation or the Katsuki epoxidation.

\section{Myers Asymmetric Alkylation ${ }^{46}-1994$}

\section{Lydia McKinstry (1966- )}

In 1994 Andrew Myers's research group at the California Institute of Technology ${ }^{47}$ published a communication describing their use of pseudoephedrine (Sudafed) as a practical chiral auxiliary for asymmetric synthesis. They discovered that reaction of pseudoephedrine-containing carboxamides with alkylating agents like benzyl bromide and methyl iodide furnished amide products in high yields and diastereomeric excess. Lydia McKinstry joined the Myers lab as a postdoc in 1994 and further developed this transformation to include alkylations with epoxides. ${ }^{48}$ McKinstry demonstrated that pseudoephedrine amide enolates (e.g., 67) readily combine with both mono- and disubstituted epoxides. For example, amide 66 is easily converted into enolate 67 which reacts with isobutylene oxide to provide amide $\mathbf{6 8}$ in good yield and excellent 
diastereoselectivity. McKinstry subsequently converted the product amides into enantioenriched ketones and lactones (e.g., 69) by reaction with methyl lithium and sulfuric acid, respectively.

\section{Scheme 20}

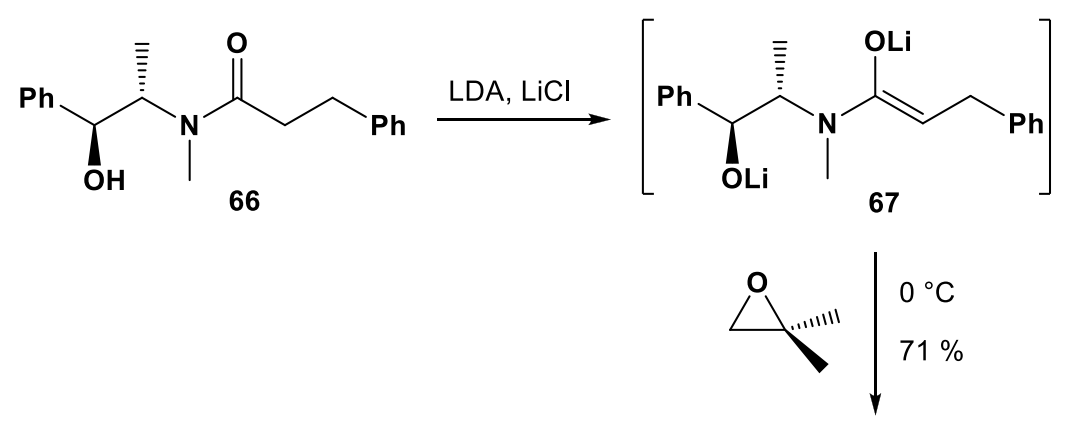

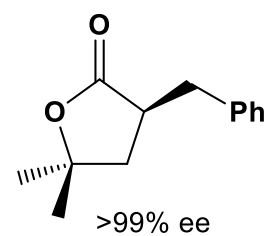

69

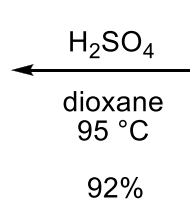

$92 \%$

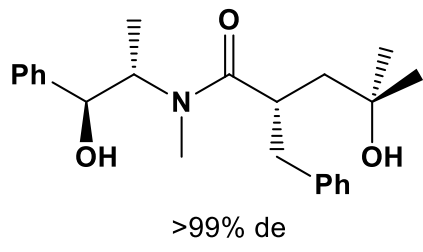

68

McKinstry's continued investigations into this chemistry, combined with the results of four other members of the Myers lab, enabled publication of the key Myers alkylation paper in $1997 .{ }^{49}$ This manuscript provides a full account of alkylation reactions and conversions of the alkylation products into enantiomerically enriched carboxylic acids, alcohols, aldehydes, and ketones. The findings of McKinstry and her colleagues have been applied by a multitude of other groups, many in natural product total syntheses. ${ }^{46}$ McKinstry's contributions were not recognized by inclusion with Myers in the name of this reaction because she played a small part in the development of the wide scope of this transformation.

Prior to Caltech, McKinstry completed her Ph.D. in 1994 at Montana State University with Thomas Livinghouse. McKinstry's career after Caltech has included two faculty positions in chemistry, first at the University of Nevada Las Vegas and currently at Evergreen College.

\section{CONCLUSION}

We hope these examples help highlight the critical role that female chemists have played in the discovery and development of important named organic reactions. Over more than a century, women have been deeply involved in key discoveries in synthetic organic chemistry. In fact, we know of seven other named reactions that relied on the efforts of women in the research lab. ${ }^{50}$ We are hopeful that all of these pioneering women are harbingers of things to come; already, graduate research labs throughout the country have 
become more diverse by gender, and the percent of women in industry and academia is climbing. ${ }^{51}$ The contributions of many of these talented chemists will surely be recognized in the future by others bestowing upon their discoveries the label of named organic reactions.

\section{ACKNOWLEDGEMENTS}

We thank the following people for their help collecting personal information about the women described in this account: James Peters, Jean Jones, Elizabeth Hardy, Dorothee Felix, Albert Eschenmoser, Claude Wintner, Katharina Gschwend, Jennifer Loebach, Tsutomu Katsuki, Lydia McKinstry, Rosa Lockwood, Kenneth Nicholas, Kaori Ando, William Roush, Kenneth Houk, Didier Astruc, Kuniko Hirata, and Shuici Kinoshita.

\section{BIOGRAPHICAL INFORMATION}

Julie A. Olson received a B.A. in chemistry at Smith College in 2010 and is currently a Fulbright Fellow in Malaysia.

Kevin M. Shea received a B.S. in chemistry from WPI in 1995 and completed his Ph.D. in Rick Danheiser's lab at MIT in 2000. He then joined the faculty at Smith College and is currently an Associate Professor of Chemistry.

\footnotetext{
${ }^{1}$ For books on the subject, see: (a) Li, J. J. Name Reactions: A Collection of Detailed Mechanisms and Synthetic Applications, $4^{\text {th }}$ ed.; Springer-Verlag: Berlin, 2009. (b) Wang, Z. Comprehensive Organic Name Reactions and Reagents; Wiley: Hoboken, NJ, 2009. (c) Name Reactions for Homologations; Li, J. J., Ed.; Wiley: Hoboken, NJ, 2009. (d) Name Reactions for Functional Group Transformations; Li, J. J., Ed.; Wiley: Hoboken, NJ, 2007. (e) Kurti, L.; Czako, B. Strategic Applications of Named Reactions in Organic Synthesis: Background and Detailed Mechanisms; Elsevier: Boston, 2005.

${ }^{2}$ Morris, P. J. Named Reactions - Forgotten Chemists Chem. Ind. 1999, 968-972.

${ }^{3}$ Drahl, C. In Names, History and Legacy Chem. Eng. News 2010, 88 (20), 31-33.

${ }^{4}$ Only Irma Goldberg, involved in two of the four reactions, is uniquely recognized for her contributions. The cases of Cläre Hunsdiecker and Gertrude Maud Robinson are less clear since they shared the same surname as their husbands, Heinz Hunsdiecker and Sir Robert Robinson, respectively.

${ }^{5}$ Evano, G.; Blanchard, N.; Toumi, M. Copper-Mediated Coupling Reactions and Their Applications in Natural Products and Designed Biomolecules Synthesis Chem. Rev. 2008, 108, 3054-3131.

${ }^{6}$ See Ref 1b, Vol. 2, pp 1569-1575.

${ }^{7}$ Creese, M. R. S. Ladies in the Laboratory II, Scarecrow Press, Lanham, Maryland; 2004, pp 184-185.

${ }^{8}$ Goldberg, I. Phenylation with Presence of Copper as Catalyst Ber. 1906, 39, 1691-1692.

${ }^{9}$ Goldberg, I.; Nimerovsky, M. Triphenylamine and Triphenylaminecarboxylic Acid Ber. 1907, 40, 24482452.

${ }^{10}$ Goldberg, I. Phenylation of Primary Aromatic Amines Ber. 1908, 40, 4541-4546.

${ }^{11}$ See Ref 1b, Vol. 2, pp 2217-2220.

12 Williams, T. I. Robert Robinson: Chemist Extraordinary; Oxford University Press: New York, 1990 and references therein.

${ }^{13}$ He was awarded the Nobel Prize in 1947 for his interest in this work.

${ }^{14}$ Robinson, G. M.; Robinson, R. A New Synthesis of Tetraphenylpyrrole J. Chem. Soc. 1918, 43, 639-645.

${ }^{15}$ It is fascinating to see the Robinsons' explanation for this step in the mechanism nearly 50 years prior to the advent of modern thinking about pericyclic reactions.

16 See Ref 1d, pp 623-629.

17 Jacques, J. In Regard to the Borodin-Hunsdiecker Reaction Compt. Rend. Acad. Sci. 1999, 2, 181-183.
} 
${ }^{18}$ Hunsdiecker, H.; Hunsdiecker, C. Degradation of the Salts of Aliphatic Acids by Bromine Ber. 1942, 75B, 291-297.

${ }^{19}$ See Ref 1c, Vol. 2, pp 293-304.

${ }^{20}$ Jacques, J. Bianka Tchoubar (1910-1990) New J. Chem. 1992, 16, 11-18 and references therein.

${ }^{21}$ Tchoubar, B. Extension of Alicyclic Rings of 1-(Aminomethyl)cycloalkanols by Nitrous Deamination.

III. Theoretical Consideration of the Reaction Mechanism of Nitrous Deamination of Amino Alcohols Bull. Soc. Chim. 1949, 16, 169-172 and references therein.

${ }^{22}$ Murray, A. W. Molecular Rearrangements Org. React. Mech. 2003, 487-615.

${ }^{23}$ Cope joined the faculty at Bryn Mawr in 1934. He moved to Columbia in 1941 and to MIT in 1945.

${ }^{24}$ Cope, A. C.; Hardy, E. M. The Introduction of Substituted Vinyl Groups. V. A Rearrangement Involving the Migration of an Allyl Group in a Three-Carbon System J. Am. Chem. Soc. 1940, 62, 441-444.

${ }^{25}$ Cope, A. C.; Hofmann, C. M.; Hardy, E. M. The Rearrangement of Allyl Groups in Three-Carbon Systems. II J. Am. Chem. Soc. 1941, 63, 1852-1857.

${ }^{26}$ Woodward, R. B.; Hoffmann, R. Selection Rules for Sigmatropic Reactions J. Am. Chem. Soc. 1965, 87, 2511-2513.

${ }^{27}$ Castro, A. M. M. Claisen Rearrangement over the Past Nine Decades Chem. Rev. 2004, 104, 2939-3002.

${ }^{28}$ Wintner, C. E. Recollecting the Institute of Organic Chemistry, ETH Zurich, 1972-1990 Chimia 2006, 60, 142-148.

${ }^{29}$ (a) Wick, A. E.; Felix, D.; Steen, K.; Eschenmoser, A. Claisen Rearrangement of Allyl and Benzyl Alcohols by N,N-Dimethylacetamide Acetals Helv. Chim. Acta 1964, 47, 2425-2429. (b) Felix, D.;

Gschwend-Steen, K.; Wick, A. E.; Eschenmoser, A. Claisen Rearrangement of Allyl and Benzyl Alcohols with 1-Dimethylamino-1-methoxyethene Helv. Chim. Acta 1969, 52, 1030-1042.

${ }^{30}$ Constantieux, T.; Rodriguez, J. Synthesis by Fragmentation and Rearrangement. In Science of Synthesis; Cossy, J., Ed.; Thieme: New York, 2005; Vol. 26, pp 413-462.

${ }^{31}$ Eschenmoster, A.; Felix, D.; Ohloff, G. New Fragmentation Reaction of $\alpha, \beta$-Unsaturated Carbonyls. Synthesis of Exaltone and rac-Muscone from Cyclododecanone Helv. Chim. Acta 1967, 50, 708-713.

${ }^{32}$ Tanabe, M.; Crowe, D. R.; Dehn, R. L.; Detre, G. The Synthesis of Secosteroid Acetylenic Ketones Tetrahedron Lett. 1967, 8, 3739-3743.

${ }^{33}$ Felix, D.; Muller, R. K.; Horn, U.; Joos, R.; Schreiber, J.; Eschenmoser, A. $\alpha, \beta$-Epoxyketone to Alkynone Fragmentation II. Pyrolytic Decomposition of Hydrazones from $\alpha, \beta$-Epoxyketones and NAminoaziridines Helv. Chim. Acta 1972, 55, 1276-1319 and references therein.

${ }^{34}$ See Ref. 1c, Vol. 1, pp 284-298.

${ }^{35}$ Nicholas is currently a professor at Oklahoma University.

${ }^{36}$ Lockwood, R. F.; Nicholas, K. M. Transition Metal-stabilized Carbenium Ions as Synthetic Intermediates. I. $\alpha$-[(Alkynyl)dicobalt hexacarbonyl] Carbenium Ions as Propargylating Agents Tetrahedron Lett. 1977, 4163-4166.

${ }^{37}$ See Ref 1d, pp 545-550.

${ }^{38}$ Inanaga, J.; Hirata, K.; Saeki, H.; Katsuki, T.; Yamaguchi, M. A Rapid Esterification by Mixed Anhydride and its Application to Large-ring Lactonization Bull. Chem. Soc. Jpn. 1979, 52, 1989-1993.

${ }^{39}$ See Ref 1b, Vol. 3, pp 2435-2438.

${ }^{40}$ Roush was at MIT from 1979-1987 and then moved to the University of Indiana. He is currently at the Scripps Research Institute in Jupiter, Florida.

${ }^{41}$ Roush, W. R.; Palkowitz, A. D.; Ando, K. Acyclic Diastereoselective Synthesis Using Tartrate Ester Modified Crotylboronates. Double Asymmetric Reactions with $\alpha$-Methyl Chiral Aldehydes and Synthesis of the C(19)-C(29) Segment of Rifamycin S J. Am. Chem. Soc. 1990, 112, 6348-6359 and references therein.

${ }^{42}$ Palucki, M. Jacobsen-Katsuki Epoxidation. In Name Reactions in Heterocyclic Chemistry; Li, J. J., Ed.; Wiley: Hoboken, NJ, 2005; pp 29-43.

${ }^{43}$ Jacobsen was on the faculty at Illinois from 1988-1993 when he moved to his current position at Harvard.

${ }^{44}$ Zhang, W.; Loebach, J. L.; Wilson, S. R.; Jacobsen, E. N. Enantioselective Epoxidation of Unfunctionalized Olefins Catalyzed by (Salen)manganese Complexes J. Am. Chem. Soc. 1990, 112, 28012803. 
${ }^{45}$ Irie, R.; Noda, K.; Ito, Y.; Matsumoto, N.; Katsuki, T. Catalytic Asymmetric Epoxidation of Unfunctionalized Olefins Using Chiral (Salen)manganese (III) Complexes Tetrahedron Asymm. 1991, 2, 481-494 and references therein.

${ }^{46}$ Mikami, K.; Shimizu, M.; Zhang, H.-C.; Maryanoff, B. E. Acyclic Stereocontrol Between Remote Atom Centers via Intramolecular and Intermolecular Stereo-communication Tetrahedron 2001, 57, 2917-2951.

${ }^{47}$ Myers joined the faculty at Caltech in 1986 and moved to his current position at Harvard in 1998.

${ }^{48}$ Myers, A. G.; McKinstry, L. Practical Syntheses of Enantiomerically Enriched $\gamma$-Lactones and $\gamma$ Hydroxy Ketones by Alkylation of Pseudoephedrine Amides with Epoxides and Their Derivatives J. Org. Chem. 1996, 61, 2428-2440 and references therein.

${ }^{49}$ Myers, A. G.; Yang, B. H.; Chen, H.; McKinstry, L.; Kopecky, D. J.; Gleason, J. L. Pseudoephedrine as a Practical Chiral Auxiliary for the Synthesis of Highly Enantiomerically Enriched Carboxylic Acids, Alcohols, Aldehydes, and Ketones J. Am. Chem. Soc. 1997, 119, 6496-6511.

${ }^{50}$ Heine Reaction - Mary Emma Fetter, Elva Mae Nicholson, Eleanor M. Johnson, Dorothy C. King; Midland Alpine Borane Reduction - Sue Greer, Deborah C. McDowell; Minisci Reaction - Mirella Cecere, Rosanna Bernardi; Regitz Diazo Transfer - Annemarie Liedhegener; Shapiro Reaction - Marsha J. Heath; Stille-Kelly Coupling - Vidya Bhushan; [1,2]- and [2,3]-Wittig Rearrangement - Lisa Lohmann ${ }^{51}$ Raber, L. R. Women Now $17 \%$ of Chemistry Faculty Chem. Eng. News 2010, 88(9), 42-43 and references therein. 